\title{
The dual kinase complex FAK-Src as a promising therapeutic target in cancer
}

This article was published in the following Dove Press journal:

OncoTargets and Therapy

10 June 2010

Number of times this article has been viewed

\author{
Victoria Bolós1,* \\ Joan Manuel Gasent, ${ }^{2, *}$ \\ Sara López-Tarruella ${ }^{3}$ \\ Enrique Grande ${ }^{\text {I,\# }}$ \\ 'Pfizer Oncology, Madrid, Spain; \\ ${ }^{2}$ Hospital Gral. Universitario Marina \\ Alta, Oncology Department, Denia \\ Alicante, ${ }^{3, \# H o s p i t a l ~ C l i ́ n i c o ~ S a n ~}$ \\ Carlos, Oncology Department, "These \\ authors contributed equally to this \\ work, ${ }^{\# C e n t e r}$ affiliated to the Red \\ Temática de Investigación Cooperativa \\ (RD06/0020/002I). Instituto de Salud \\ Carlos III (ISCIII), Spanish Ministry of \\ Science and Innovation
}

Correspondence: MVictoria Bolós Pfizer Oncology, Avda. de Europa 20B, Alcobendas-Madrid, ZIP 28I08, Spain Tel +34 9l 4909660 Fax +34 9| 490975 I Email mariavictoria.bolos@pfizer.com
Abstract: Focal adhesion kinase (FAK) and steroid receptor coactivator (Src) are intracellular (nonreceptor) tyrosine kinases that physically and functionally interact to promote a variety of cellular responses. Plenty of reports have already suggested an additional central role for this complex in cancer through its ability to promote proliferation and anoikis resistance in tumor cells. An important role for the FAK/Src complex in tumor angiogenesis has also been established. Furthermore, FAK and Src have been associated with solid tumor metastasis through their ability to promote the epithelial mesenchymal transition. In fact, a strong correlation between increased FAK/Src expression/phosphorylation and the invasive phenotype in human tumors has been found. Additionally, an association for FAK/Src with resistances to the current anticancer therapies has already been established. Currently, novel anticancer agents that target FAK or Src are under development in a broad variety of solid tumors. In this article we will review the normal cellular functions of the FAK/Src complex as an effector of integrin and/or tyrosine kinase receptor signaling. We will also collect data about their role in cancer and we will summarize the most recent data from the FAK and Src inhibitors under clinical and preclinical development. Furthermore, the association of both these proteins with chemotherapy and hormonal therapy resistances, as a rationale for new combined therapeutic approaches with these novel agents, to abrogate treatment associated resistances, will also be reviewed.

Keywords: SRC, FAK, cancer, therapeutic target, FAK inhibitors, SRC inhibitors

\section{The nonreceptor tyrosine kinases FAK and SRC}

\section{The FAK-SRC complex in the integrin} and tyrosine kinase receptor setting

Integrins are a family of transmembrane receptors that link the extracellular matrix (ECM) and the intracellular actin-cytoskeleton. These cell-matrix areas of adhesion are known as focal adhesion (FA) contacts/areas. Integrins cluster when they bind to ECM. Integrin clustering has a structural role but also induces the activation of intracellular signaling pathways that lead to important cellular responses such as proliferation, survival, migration and invasion in both normal and tumor cells. ${ }^{1}$ In this setting, the linked activities of two nonreceptor intracellular tyrosine kinases, focal adhesion kinase (FAK) and steroid receptor coactivator (Src), is a common intracellular point of convergence in the signaling initiated by this integrin-ECM interaction. In response to the clustering, FAK associates to the cytoplasmic tail of the integrin and in response to this association FAK phosphorylates at its tyrosine residue 397 (Y397). Although this Y397 phosphorylation is mainly due to autophosphorylation; transphosphorylation by growth factors might also occur. This phosphorylated tyrosine provides a docking site for Src 
(Figure 1). ${ }^{2}$ The tyrosine kinase Src, then, phosphorylates additional sites on FAK, leading to further increased activity of FAK and allowing the recruitment of proteins that contain Src homology 2 (SH2) domains such as Grb2 and PI3K. ${ }^{3}$ The mutually activated FAK/Src complex then initiates a cascade of phosphorylation events of new protein-protein interactions to trigger several signaling pathways that eventually leads to different cellular responses. For instance, Grb2, once bound to FAK can recruit SOS into the complex and activates the downstream Ras-MAPK pathway and/or may also transduces the signal through the activation of the PI3K-Akt cascade. ${ }^{3-5}$

Adhesion is a hallmark of solid cancer cells and integrins are a nexus between intracellular signaling and cytoskeletal dynamics; besides, integrin-mediated signaling also intersects with growth factor-mediated signaling through various levels of cross-talk. In this complex network, the FAK/Src complex also transduces signals from tyrosine kinase receptors (TKRs) or integrates signals from both, integrins and TKRs, (see Figure 1) in normal and tumor cells. ${ }^{3,4}$ As an illustration of this connection in breast cancer, transforming growth factor $\beta$ (TGF- $\beta$ ) has recently been found to be able to induce membrane-proximal clustering of human EGF (Epidermal Growth Factor) receptor 2, (HER2) and integrins by activating Src-FAK and receptor association to the cytoskeleton. ${ }^{6}$

Platelet-derived growth factor receptor (PDGF-R), epidermal growth factor receptor (EGF-R), fibroblast growth factor receptor (FGF-R), insulin-like growth factor1 receptor (IGF-1R), hepatocyte growth factor (HGF-R), colony-stimulating factor-1 receptor (CSF-1R) or, stem cell factor receptor (SCF-R) are also TKRs that may transduce their signal by FAK/Src activation. As a consequence, the FAK/Src complex is potentially involved in different steps of tumorogenesis and further growth and metastatic progression of malignant tumors. ${ }^{7,8}$

The increased expression or activity of FAK and/or Src in tumors is associated with a more invasive and aggressive phenotype and has lead to the development of Src and FAK inhibitors as new anticancer drugs. ${ }^{9-12}$ These drugs are able to block proliferation, survival, angiogenesis and/or migration/invasion in preclinical tumor models ${ }^{13}$ and some of them have already shown preliminary antitumor activity in clinical trials with cancer patients. ${ }^{14-19}$

\section{FAK and Src structure}

c-Src was the first characterized human oncogene. In 1909 Peyton Rous identified the Rous Sarcoma's Virus (RSV). ${ }^{20,21}$ Later, in 1958, the v-Src gene was identified as the cause that allowed RSV to produce the sarcoma when the virus infected healthy chickens. The v-Src gene was taken up by RSV and incorporated into its genome conferring the virus the advantage of being able to stimulate uncontrolled proliferation in host chicken cells. Finally the human homologue of the v-Src gene, c-Src, was characterized as the first oncogene in humans. ${ }^{22}$

c-Src is a nonreceptor tyrosine kinase. The Src family comprises of eight members in humans (Src, Fyn, Yes, Lyn, Lck, Hck, Blk and Fgr) with a molecular weight between $52-62 \mathrm{KDa} \cdot{ }^{22,23}$ Each Src kinase family member is comprised of six domains. A SH4 domain placed at the $\mathrm{N}$-terminal tail is involved in targeting Src to the plasmatic membrane. Adjacent to the SH4 domain, a region that is specific to each Src family member followed by a SH3 and a SH2 domain, both of them involved in the interaction of Src with other intracellular proteins (Figure 2). ${ }^{23}$ Additionally, in the C-terminal tail, there is an SH1 domain involved in adenosine tri-phosphate (ATP) and substrate binding. This SH1 domain shows tyrosine kinase activity. The phosphorylation in the Y419 residue of the SH1 domain is required for maximum kinase activity. Immediately adjacent to the SH1 domain, there is another C-terminal region that acts as a negative regulatory domain that is itself regulated by phosphorylation. After phosphorylation of the Y530 residue, placed in this negative regulatory domain, Src undergoes conformational changes and becomes inactive. ${ }^{23}$ Src activation is regulated at many different levels. In response to a signal stimuli Src translocates from the cytosol to the membrane where it will be activated by phosphorylation, the intracellular localization of $\mathrm{Src}$ is therefore one of the key regulatory mechanisms that control Src activation..$^{24}$ In addition the binding of FAK to the SH2 domain of Src relieves its autoinhibitory interaction that leads to the activation of Src. Once activated, Src phosphorylates FAK on a number of additional tyrosine residues, leading to further increased activity of FAK. ${ }^{2,23,25}$ In this sense, FAK acts as a molecular scaffold protein to activate and recruit Src to its substrates.

FAK was first identified in the search for proteins that where tyrosine phosphorylated in an integrin dependent manner and also in Src transformed fibroblasts as a key substrate of Src oncoprotein. ${ }^{26}$ It was described as a focal adhesion-associated nonreceptor protein tyrosine kinase $\mathrm{e}^{27,28}$ ubiquitously expressed and encoded by an evolutionarily highly conserved gene.

FAK harbors a central region with kinase activity that is flanked by a large N-terminal region that contains the erythrocyte band four 1-ezrin-radixin-moesin (FERM) domain and by a C-terminal region that contains the focal adhesion 


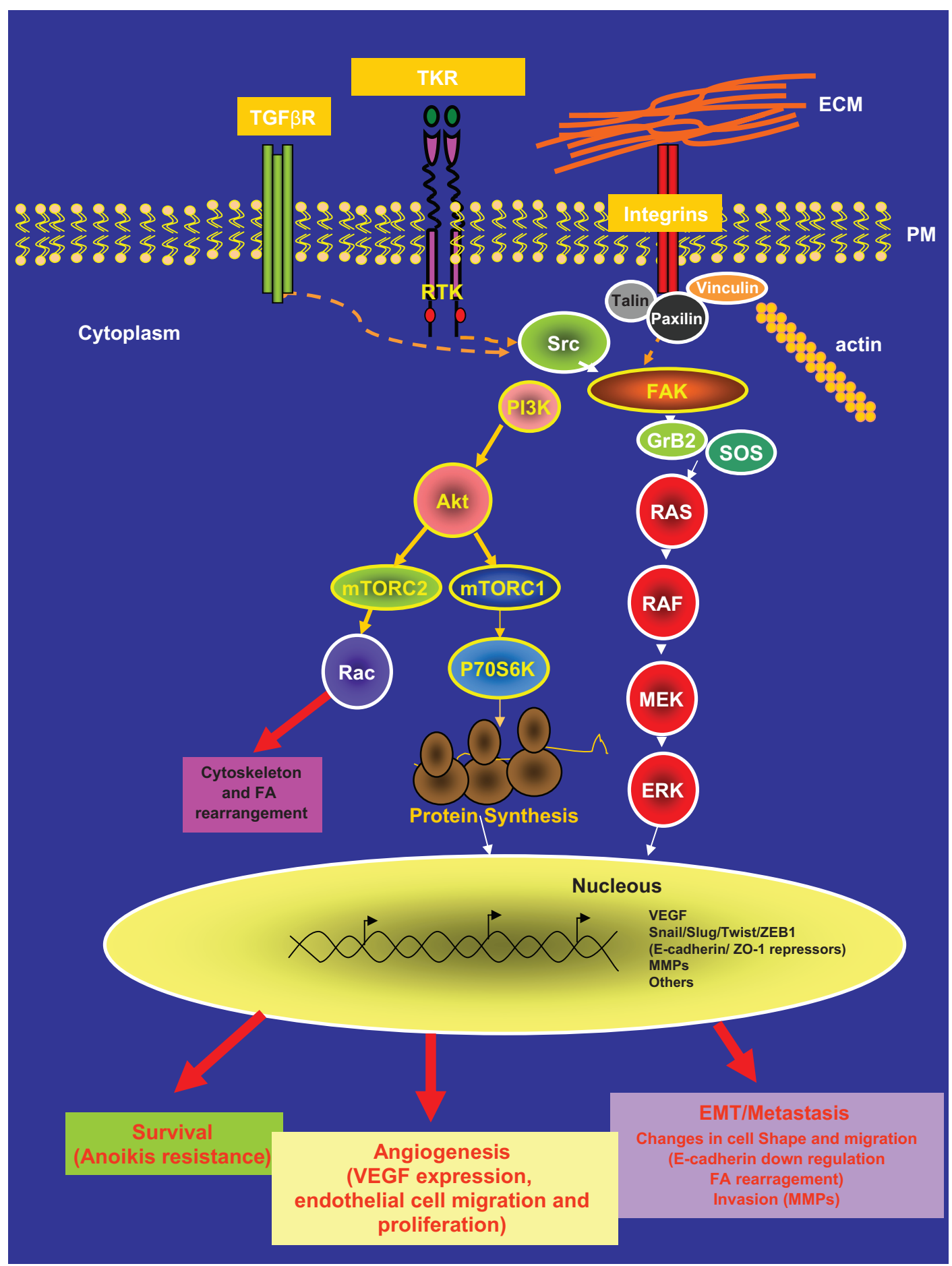

Figure I FAK/Src complex mediated signaling pathway.

Notes: The FAK/Src complex transduces signals from a variety of membrane receptors such as tyrosine kinase repectors and integrins through the activation of intracellular signaling pathways such as PI3K-AKt and Ras-MAPK to reach a cellular response.

Abbreviations: ERK, extracellular signal regulated kinase; FA, focal adhesions; MEK, mitogen-activated protein; FAK, focal adhesion kinase;VEGF, vascular endothelial growth factor; MMPs, matrix metalloproteinases.

targeting (FAT) domain. The Y397 residue, immediately adjacent to the kinase domain, is autophosphorylated in response to the clustering of integrins. This autophosphorylation increases the catalytic activity of FAK and creates a high affinity binding site for the SH2 domain of Src. This interaction recruits and activates Src. The formation of the complex with Src is the most critical event in FAK-associated signaling. Src binds the Y397 residue and phosphorylates other FAK residues including Y576 and Y577 placed on the catalytic loop of the kinase and Y861 that are important for 


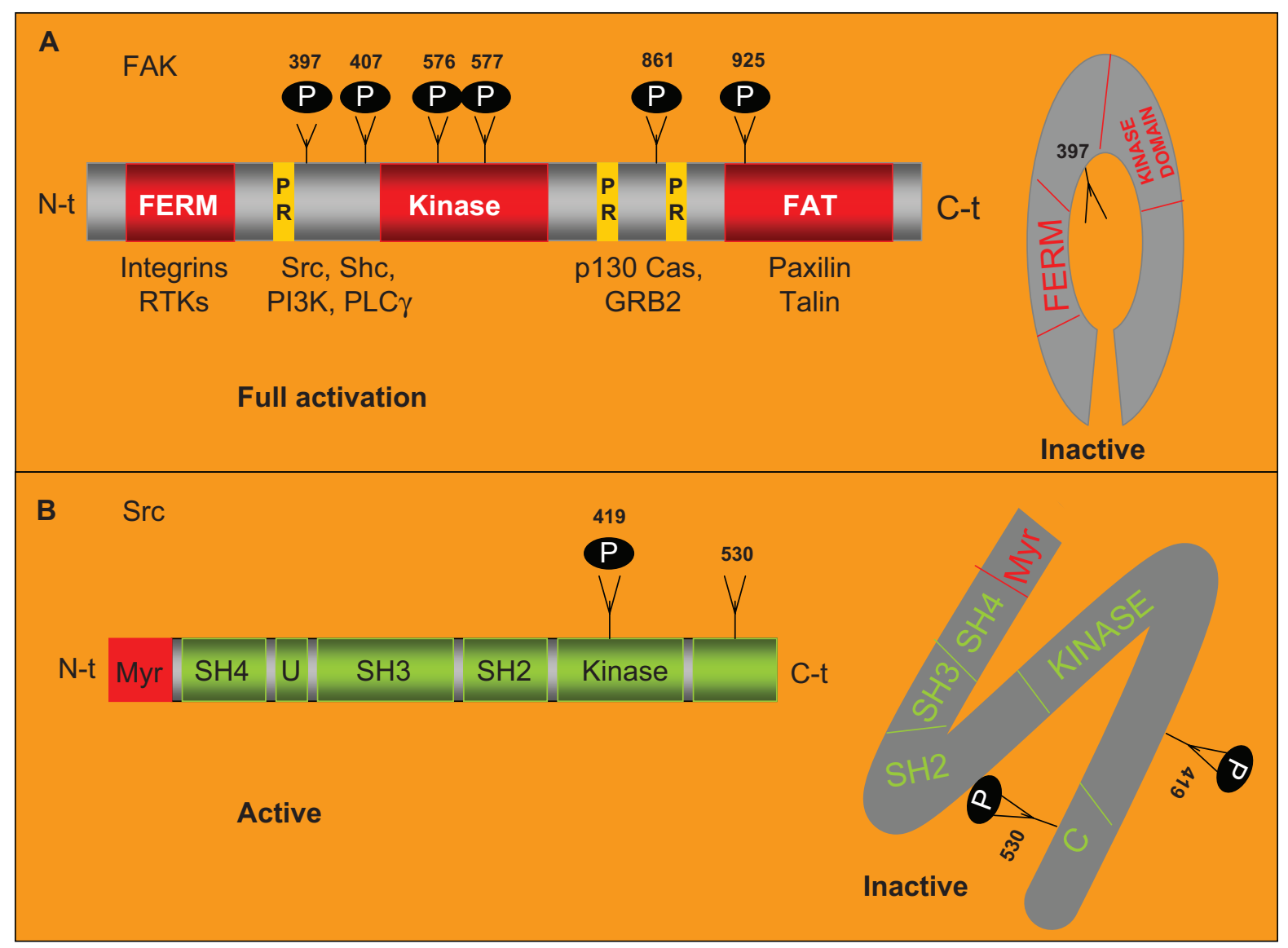

Figure 2 FAK and Src structure.

Notes:A) FAK structure. FAK harbors a central region with kinase activity that is flanked by a $\mathrm{N}$-terminal region that contains the FERM domain and by a C-terminal region that contains the FAT domain. The autophosphorylation in its Y397 residue increases its catalytic kinase activity and allows the binding of specific intracellular proteins. FAK is phosphorylated by Src in its Y 576 and Y577 residues allowing its full catalytic activity. In absence of stimulus, the FERM domain works as a negative regulator of FAK activity through its interaction with the kinase domain preventing the phosphorylation in Y397. In response of stimuli, the FERM domain interacts with the cytoplasmic tail of the integrins. Allowing the autophosphorylation of FAK in this tyrosine. The FAT domain, placed in the C-terminal region, mediates the co-localization of FAK with the FA areas through the interaction of FAK with the FA associated proteins talin and paxillin. Two proline-rich domains (PR) mediate the interaction of FAK with SH3 containing proteins such as pI 30 CAS. B) Src structure. Src is comprised of six domains: a SH4 involved in targeting Src to the plasmatic membrane, a region U that is specific of each Src family member, a SH3 and a SH2 domain involved in the interaction of Src with other intracellular proteins and a SHI domain involved in ATP and substrate binding. The phosphorylation in $\mathrm{Y} 4 \mathrm{I} 9$ residue of the $\mathrm{SHI}$ domain is required for maximum kinase activity. Placed immediately adjacent to the SHI domain there is a negative regulatory domain. After phosphorylation of the $Y 530$ residue, in the negative regulatory domain, Src becomes inactive.

Abbreviations: FAK, focal adhesion protein; RTK, tyrosine kinase receptor; FERM, Band 4.I Ezrin, Radixin, Moesin; PI3K, phosphoinositide 3 kinase.

full catalytic activity of FAK. Y925 has been also identified as an important site for phosphorylation by Src, which involves Src in induced epithelial mesenchymal transitions (EMTs). ${ }^{29,30}$ In the absence of stimuli from integrins and/or TKRs, the FERM domain works as a negative regulator of FAK activity. This domain interacts with the kinase domain preventing Y397 phosphorylation. Conversely, in response to co-clusters of integrins and TKRs, the FERM domain interacts with the cytoplasmic tail of the integrin allowing FAK-autophosphorylation in this Y397 residue. The FAT domain, placed in the C-terminal region, mediates the colocalization of FAK with the FA areas through the interaction of FAK with the FA associated proteins talin and paxillin. Furthermore, two proline rich domains, placed adjacent to the FAT domain, mediate the interaction of FAK with SH3 containing proteins such as p130CAS. ${ }^{9,11}$ The ability of FAK to promote the activation of p130CAS depends on Src activity. Although the scaffold function of FAK to recruit Src to its substrates is has already been well established, however less is known regarding FAK kinase activity.

Besides integrins, the N-terminal region of FAK also interacts with TKRs, and this interaction may be involved in the regulation of FAK activity and in addition in cross-talks between integrins and TKRs. ${ }^{31}$ Phosphorylation of FAK. Y861 promotes association of FAK with the $\alpha_{y} \beta_{5}$ integrin following vascular endothelial growth factor (VEGF) stimulation. ${ }^{32}$

Different FAK isoforms from alternative splicing have been found: FAK, proline rich tyrosine kinase 2 (PYK2) and FAK related nonkinase (FRNK). ${ }^{9}$ FRNK lacks the catalytic 
domain working as a FAK inhibitor competing with nontruncated endogenous FAK for the localization at FA areas. ${ }^{33}$

FAK activity is under strict regulation by a variety of kinases and phosphatases such as glycogen synthetase kinase 3 type $\beta$ (GSK3 $\beta$ ), tyrosine phosphatase SHP-2, serine/ threonine protein phosphatase type 1 as well as by Src..$^{3,34,35}$

\section{FAK and Src and their function in normal and tumor cells}

Although, most available articles in the literature show FAK and Src as independent proteins, the current idea that both proteins work as a protein complex in the cellular signaling networks is emerging. FAK would form a binary complex with Src family kinases which can phosphorylate other substrates and trigger multiple intracellular signaling pathways that would induce different cellular responses.

FAK and Src are not only critical modulators of signaling pathways mediated by TKRs and integrins, they also respond to stimuli from $\mathrm{G}$ protein-coupled receptors, cell-cell adhesion proteins (ie, cadherins) and steroid hormone receptors to control a variety of normal and oncogenic cellular responses such as cell survival, proliferation and migration/invasion. . $^{4,22,23,34,36,37}$

FAK-null embryos exhibit an early embryonic lethal phenotype. ${ }^{38}$ These embryos show multiple defects, including a disorganized cardiovascular system due to extensive defects in angiogenesis and vasculogenesis. ${ }^{38}$ Accordingly, over expression of FAK in vascular endothelial cells promotes angiogenesis. ${ }^{39}$ In addition, conditional deletion of FAK in adult mouse epithelium was not lethal, and probably due to a functional compensatory effect mediated by its related family member PYK2.$^{40}$ Although PYK2 knock out mice develop normally except they do exhibit defective macrophage migration. ${ }^{41,42}$ The above data suggested that endothelial cells may posses an adaptive capacity to switch to PYK2 dependant signaling after deletion or inhibition of FAK. Thus, FAK and PYK2 inhibition may result in an antiangiogenic effect.

An interesting interaction has also been reported between FAK and the tumor suppressor protein p53, via the FERM domain that triggers p53 degradation, so that loss of FAK results in activation of $\mathrm{p} 53$ which could eventually suggest new approaches to trigger cytotoxic drug induced apoptosis. ${ }^{43}$

Although, Src-null mice were viable, the analysis of homozygous mutants showed that they were deficient in bone remodeling (they had an impaired osteoclast function) and also developed osteopetrosis. This phenotype demonstrated that Src is not required for general cell viability possibly due to a Src functional overlap with other related tyrosine kinases such as FAK. Therefore, Src may play an essential role in bone formation. ${ }^{44}$ Accordingly, cancer patients treated with a Src inhibitor showed reduced serum levels of bone resorption markers suggesting Src inhibitors as a possible effective treatment for established bone metastasis. ${ }^{45,46}$

In normal adult tissues and tumor cells, FAK and Src control many important biological processes within the cell. They have been associated with responses of cell growth and survival. ${ }^{9,10}$ In addition, they have also been involved in anoikis (apoptosis induced when anchorage-dependent cells detach from the surrounding ECM) resistance in tumor cells. ${ }^{47-50}$ Hence, FAK/Src activation may promote the anchorage-independent growth/transformation of tumor cells through the inhibition of the apoptotic response. ${ }^{48,49}$ FAK activation, in response to integrins, has an important role in FA turnover/rearrangement. This process is crucial for cell spreading and migration in physiological and pathological processes (ie, FA turnover is essential for EMTs during the metastatic behavior of tumor cells and in endothelial cell migration during tumor angiogenesis). ${ }^{9}$ Phosphorylation of FAK-Y925 is the major Src-specific phosphorylation event that is associated with integrin adhesion dynamics and E-cadherin deregulation during Src-induced EMT. ${ }^{29,30}$

Furthermore, FAK has already been found, at elevated levels, in the majority of human cancers (head and neck, colon, breast, prostate, liver, thyroid, and others), particularly in highly invasive metastases ${ }^{51}$ High levels of Phospho-FAK Y397 has already been found in: ovarian invasive tumors; ${ }^{52}$ acute myeloid leukemia; ${ }^{53}$ squamous cell carcinoma of the laryn: ${ }^{54}$ invasive cervical carcinoma; ${ }^{55}$ invasive human colon cancer cells $;{ }^{56}$ medullary thyroid cancer cell lines $;{ }^{57,58}$ human pancreatic cancer cells; $;{ }^{59}$ glioma cells; ${ }^{60}$ and other tumor types. Furthermore, high levels of FAK phosphorylated in other tyrosine residues have already been found in specific tumor types. Papillary thyroid cancer samples show high phosphor-Y861-FAK levels and high levels of phopho-Y861-FAK have also been correlated with sensitivity to the Src inhibitor AZD0530 in papillary and also in anaplastic thyroid cancer models. ${ }^{61}$ Although, the relationship between Src and cancer progression is best documented in colon and breast cancer. ${ }^{10,62}$ Src over expression or over activation has also been shown in a variety of human biopsies from primary tumors and their metastases (Figure 3). ${ }^{23}$

An additional pro-angiogenic role for FAK and Src signaling in tumors has also been suggested. ${ }^{63-69}$ FAK 
expression has been found in tumor endothelial cells from grade III and IV astrocytoma biopsies; whereas FAK expression was absent in endothelial cells of normal brain biopsies. ${ }^{63}$ Accordingly, tumor endothelial cells transfected with FRNK (a negative FAK regulator) showed less migration in vitro than control cells; suggesting that FAK is involved in tumor-angiogenesis, at least in part, through the induction of endothelial cell migration. ${ }^{63}$ Preclinical data from prostate cancer cell lines have also suggested a role for FAK signaling in the induction of VEGF expression in tumor cells. ${ }^{70}$ Additionally, an intracellular cross-talk between the Ang-1 TKR (Tie-2) involved in angiogenesis in tumors and integrin pathways has also been shown. ${ }^{71}$ The binding of integrin $\alpha 1 \beta 5$ to ECM-glycoproteins may lead to the association of Tie- 2 with integrin $\alpha 1 \beta$. The stimulation of Tie- 2 by Ang-1 may promote the recruitment of FAK to the TKR-integrin areas inducing an endothelial cell response (sprouting and stabilization of the new tumor vessels). ${ }^{71}$ Src has also been associated with VEGF production in tumor cells. ${ }^{66}$ In fact, Src inhibition decreases angiogenesis in vivo. ${ }^{68,69}$
Immunohistological data about the expression/correlation between active FAK/Src on primary tumors and on their metastases is still awaited, to explore the value of FAK/Src as predictors of tumor outcome.

In fact, as we will review below, a link for FAK/Src with chemoresistance has already been reported in tumor models. In fact, FAK downregulation enhances docetaxel cytotoxicity in ovarian cancer cells. ${ }^{72}$ Moreover, FAK downregulation also increases gemcitabine chemosensitivity in pancreatic cancer cells. ${ }^{73}$ Accordingly, a variety of reports show a role for Src in the promotion of chemoresistance. ${ }^{74-77}$ Src inhibitors have already shown single agent activity in cancer patients after their progression to chemotherapy. ${ }^{78}$ Src inhibition promotes chemosensitivity in pancreatic cancer cells. ${ }^{74}$ In addition, a combination of 5-fluorouracil (5-FU) and a Src inhibitor in 5-FU-resistant human pancreatic cancer cell lines restored 5-FU-induced apoptosis. ${ }^{74}$ The potential mechanism for 5-FU chemosensitivity induced by Src inhibitors might be associated with the inhibition of the epidermal growth factor receptor-AKT (EGFR-AKT) pro-survival pathway induced by 5-FU. Fur-

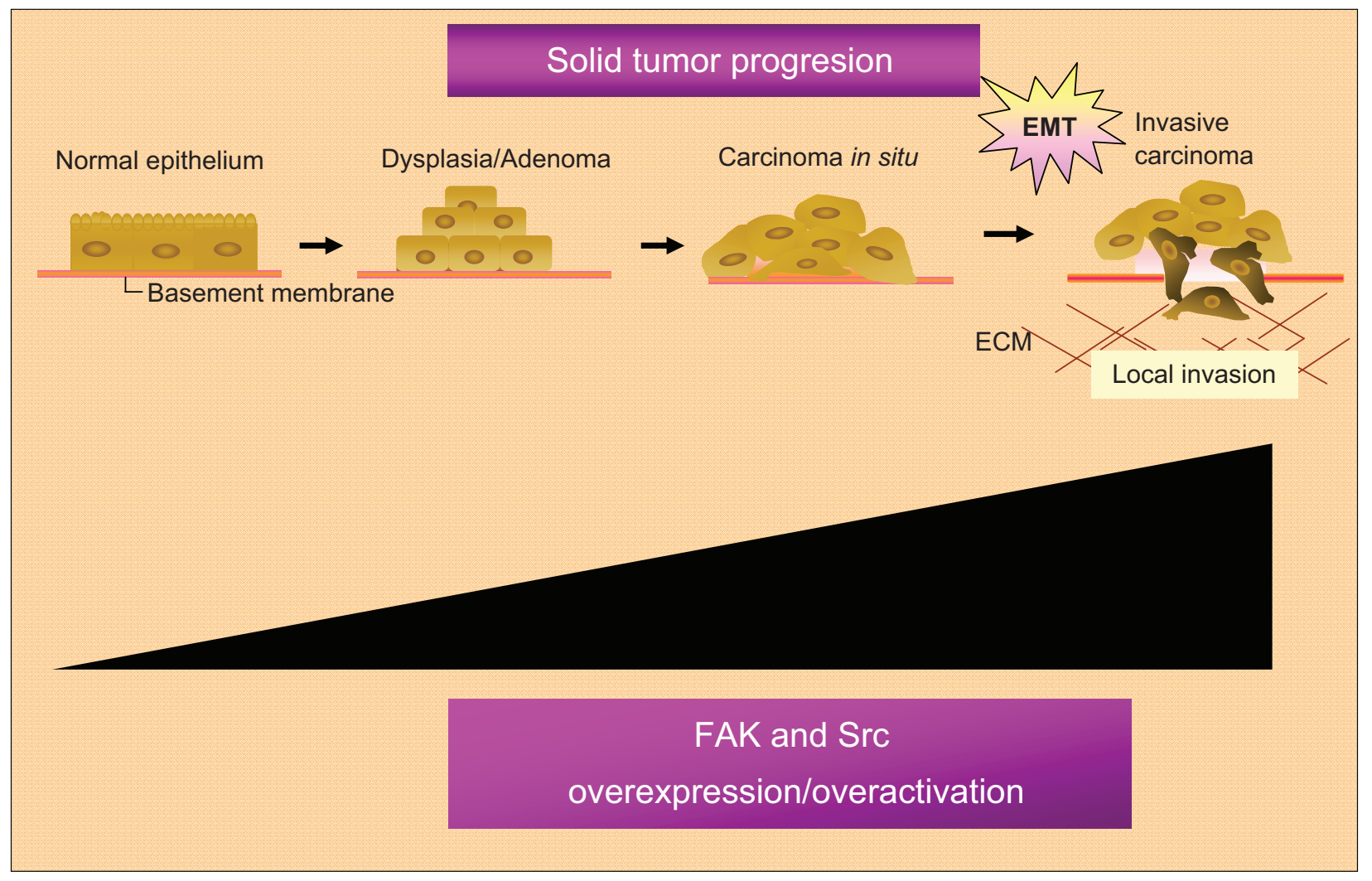

Figure 3 Role of the FAK-Src complex in the malignant progression of solid tumors.

Notes: FAK and Src play a critical role in solid tumor progression mainly through its ability to promote the epithelial-mesenchymal transition associated with the metastatic behavior of solid tumors.

Abbreviations: ECM, extracellular matrix; EMT, epithelial mesenchynal transitions; FAK, focal adhesion kinase; Src, steroid receptor coactivator. 
thermore, a role for Src in mediating acquired endocrine resistance is also well established. ${ }^{10}$

Other FAK family members have also been associated with cancer. In fact, Pyk2 also shows a high expression and an association with tumor progression in a variety of tumor types such as: astrocytomas; breast; glioma; prostate; hepatocarcinoma; and nonsmall cell lung cancer. ${ }^{79-83}$ In addition, other Src family members have also been associated with solid and hematological tumors; and inhibitors against Src family members are under development as new anticancer drugs. $^{84}$

\section{FAK-Src and tumor associated epithelial mesenchymal transition}

Epithelial mesenchymal transition (EMT) is a complex of cellular and molecular processes by which epithelial cells acquire mesenchymal and migratory properties.$^{85}$ EMT takes place during critical phases of embryonic development and is also a crucial step in the infiltration and progression in solid tumors. Hallmarks of EMT include loss of cell-cell contacts, induction of FA turnover and increased expression of mesenchymal (fibronectin, vimentin, N-cadherin, $\alpha$-smooth muscle actin, and others) and invasiveness (ie, metalloproteinases) markers. ${ }^{86}$ The EMT is at the convergence of different molecular pathways involving cell survival and resistance to apoptosis, invasion and tumor angiogenesis, metastasis and drug resistance in advanced tumors. $^{87}$

A critical molecular feature in the loss of cell-cell contacts during EMT is the downregulation of the adhesion molecule E-cadherin (delocalization/loss of E-cadherin expression). A variety of membrane receptors such as integrins, TKRs, serine-threonine kinase receptors are able to induce E-cadherin downregulation during development and tumor progression through the activation of specific intracellular signaling cascades such as Ras-MAPK and PI3K-Akt-mTOR. In fact, transcriptional repressors (Snail, Slug, Twist, or ZEB1/2) involved in EMTs during development are also induced in response to EMT stimuli to repress E-cadherin expression during tumor progression. ${ }^{86}$ Plenty of evidence suggests that FAK and Src, through its ability to integrate signals from numerous signaling receptors, plays a critical role in tumor-associated EMTs promoting intracellular signaling pathways that lead to the induction of E-cadherin repressors and to the subsequent E-cadherin downregulation as well as that promote FA turnover to allow tumor cell migration/invasion (Figure 1B). ${ }^{88-91}$

\section{New anticancer drugs that target FAK and Src}

Based on evidence that supports FAK as a molecular scaffold protein, activated by Src to recruit its substrates; and that Src, as a tyrosine kinase is involved in the catalytic activation of FAK, and triggers FAK kinase activity to promote a variety of cellular responses during tumor progression, preclinical and clinical studies with new agents that employ different mechanisms for the blockade of FAK or Src kinases are currently underway., ${ }^{9,10}$ We show below a summary of the most advanced FAK and Src inhibitors under development (see Table 1).

Historically the first drugs synthesized with the aim of inhibiting T-cell activation via the Src family kinases Lck and Fyn were PP1 and PP2. The latest one is very selective for Src family kinases (SFKs). After PD173955 and PD173956 emerged with a lower selectivity than that of PP2, since these compounds were inhibitors of; Abl, Csk, platelet derived growth factor receptor (PDGFR) and EGFR. CGP76030 and CGP77675 were also multi-targeted agents against SFKs, Abl, EGFR and VEGF receptor (VEGFR) and SFKs, EGFR, FAK, and VEGFR, respectively. A third generation of molecules characterized by their higher potency in enzyme assays and their dual inhibition of c-Abl in a variety of imatinib-resistant c-Abl mutations appeared. The strong activity against $\mathrm{c}-\mathrm{Abl}$ together with the potent anti-Src activity is explained by the strong structural similarity of the ATP binding domains in both kinases. The dual selectivity speeded up the development of these compounds.

At present, researchers are strongly focused on the study of the potential therapeutic benefits from the use of ATP-competitive kinase inhibitors against FAK and Src. These inhibitors interact with the ATP-binding pocket of FAK or Src and subsequently prevent FAK and Src autophosphorylation and therefore their activation. ${ }^{11}$

\section{Dasatinib}

Dasatinib (BMS-354825) is an orally active small multiselective inhibitor, which inhibits the kinases Src and Abl with IC50 values of 0.55 and $3.0 \mathrm{nM}$, respectively. ${ }^{92}$ Dasatinib also inhibits other Src family members such as Fyn (half maximal inhibitory concentration [IC50] of $0.2 \mathrm{nM}$ ), LcK (IC50 of $1.1 \mathrm{nM}$ ) and Yes (IC50 of $0.4 \mathrm{nM}$ ). ${ }^{92}$ Dasatinib blocks the wild type chimeric Bcr-Abl protein which arise from Philadelphia chromosome. ${ }^{93}$ Dasatinib is a 20 -fold more potent inhibitor than imatinib in cells expressing wild-type Bcr-Abl hybrid protein and it also has an antitumoral effect in those tumor cells expressing Bcr-Abl imatinib-resistant mutants..$^{93}$ Dasatinib is also able to inhibit the tyrosine kinase receptors c-KIT, PDGFR- $\beta$ 
Table I Summary of FAK and Src inhibitors under clinical and preclinical development

\begin{tabular}{|c|c|c|c|c|c|c|}
\hline \multirow[t]{2}{*}{ Drug } & $\begin{array}{l}\text { Target } \\
\text { (IC50) }\end{array}$ & IC50 & IC50 & IC50 & \multirow[t]{2}{*}{ Preclinical activity } & \multirow[t]{2}{*}{ Clinical activity } \\
\hline & Src & FAK & Abl & IGFIR & & \\
\hline $\begin{array}{l}\text { BMS-354825 } \\
\text { (Dasatinib) }\end{array}$ & $0.55 \mathrm{nM}$ & & $3.0 \mathrm{nM}$ & & $\begin{array}{l}\text { Solid and hematological } \\
\text { tumor models }\end{array}$ & $\begin{array}{l}\text { Approved in Imatinib } \\
\text { refractory CML and } \\
\text { Philadelphia chromosome + ALL, } \\
\text { Phase I-2 clinical trials in } \\
\text { solid and hematological tumors } \\
\text { are underway }\end{array}$ \\
\hline PF-562,27I & 797 nM & $\begin{array}{l}1.5 \mathrm{nM} \\
(0.7 \mathrm{ng} / \mathrm{mL})\end{array}$ & & $>500 \mathrm{nM}$ & $\begin{array}{l}\text { Colon, breast, prostate, } \\
\text { pancreatic and lung tumor } \\
\text { models }\end{array}$ & $\begin{array}{l}\text { Phase I clinical trial in solid } \\
\text { tumors has been already } \\
\text { communicated }\end{array}$ \\
\hline TAE-226 & & $\begin{array}{l}100 \mathrm{nM} / \mathrm{L} \\
=100 \mathrm{nM}\end{array}$ & & $\begin{array}{l}300 \mathrm{nM} / \mathrm{L} \\
=300 \mathrm{nM}\end{array}$ & $\begin{array}{l}\text { Glioma and human } \\
\text { pancreatic tumor cell lines }\end{array}$ & Not yet \\
\hline AZD0530 & $\begin{array}{l}\leq 4 \mathrm{nM} \\
27 \mathrm{nM}\end{array}$ & & & & $\begin{array}{l}\text { Skin, prostate, breast } \\
\text { and pancreatic tumor models }\end{array}$ & $\begin{array}{l}\text { Phase I-2 clinical trial } \\
\text { underway }\end{array}$ \\
\hline $\begin{array}{l}\text { SKI-606 } \\
\text { (Bosutinib) }\end{array}$ & $3.8 \mathrm{nM}$ & & & & CML, colon and breast models & $\begin{array}{l}\text { Phase I clinical trial has been } \\
\text { already communicated, Ph II } \\
\text { clinical trial in CML patients } \\
\text { after imatinib failure under } \\
\text { development }\end{array}$ \\
\hline
\end{tabular}

Abbreviations: FAK, focal adhesion kinase; CML, chronic myelogenous leukemia; IGF, insulin-like growth factor; IC, inhibitory concentration.

and ephrins (EPHA2). ${ }^{92}$ Dasatinib has already shown to have broad preclinical activity in solid and hematological tumor models. ${ }^{14,92}$ It has already been approved by the Food and Drug Administration (FDA) and by the European Medicines Agency (EMEA) for the second line treatment of imatinib-refractory chronic myelogenous leukemia (CML) and Philadelphia chromosome-positive acute lymphoblastic leukemia (ALL). ${ }^{14}$ Currently, phase I/II clinical trials with dasatinib as a single agent or in combination are underway in a variety of solid and hematological tumors, based on the capability of dasatinib for blocking the activity Src family members. ${ }^{94}$ Besides effectiveness in hematologic malignancies, dasatinib can suppress tumor growth in human breast cancer, human prostate, colon, ovarian, and lung cancer lines. ${ }^{95-100}$

\section{AZD0530}

AZD0530 is another novel, orally administered, potent, and highly selective inhibitor of Src (IC50 value $\leq 4 \mathrm{nM}$ ), other Src family members like LcK and Yes (both with IC50 values $<4 \mathrm{nM}$ ) and $\mathrm{Abl}$ as well. ${ }^{101}$ Preclinical activity has been shown in: skin; breast; prostate; and pancreatic tumor models ${ }^{101}$ as well as estrogen receptor-positive breast cancer models ${ }^{102}$ where the combination of AZD0530 with tamoxifen ${ }^{103}$ and aromatase inhibitors ${ }^{104}$ prevented hormonal therapy resistance. This combination also shows an additive effect of delaying the growth of breast cancer cells. ${ }^{105}$

A variety of phase I and II clinical trials are currently underway with AZD0530 in monotherapy or in combina- tion, in patients with solid tumors based on its capability to inhibit Src. ${ }^{106}$ Another possible use of AZD0530 has been recently reported. Based upon the hypothesis that Src could be involved in the development of metastases in xenograft modes where the growth of the primary tumor was controlled by radiation; this report shows that those tumors from mice receiving AZD0530 regress more quickly following radiotherapy than their control counterparts. ${ }^{107}$

\section{Bosutinib}

Bosutinib (SKI-606) is a potent, orally administered, bioavailable, dual Src (IC50 value of $3.8 \mathrm{nM}$ ) and Abl inhibitor which has already shown to have an antitumoral effect in chronic myelocytic leukemia (CML), colon, prostate and breast cancer models. ${ }^{108,109}$ Preclinical breast cancer models showed a decrease in in vitro cell motility and invasion and in vivo metastases after bosutinib treatment. ${ }^{110}$ A phase I clinical trial with bosutinib has been published showing; drugrelated dose-limiting toxicity of grade 3 diarrhea and grade 3 rash (1 pt) with $400 \mathrm{mg}$ being selected as the maximum tolerated dose. ${ }^{111}$ Currently, phase II, proof of concept clinical trials, in patients with CML who had failed to improve with Imatinib, and in patients with solid tumors, are underway. ${ }^{112}$

\section{PF-562,27I}

PF-562,271 is a potent ATP-competitive, small molecule inhibitor of both FAK and the related kinase Pyk2 (IC50 values of $1.5 \mathrm{nM}(0.7 \mathrm{ng} / \mathrm{mL})$ and $14 \mathrm{nM}(7 \mathrm{ng} / \mathrm{mL})$, respectively). 
PF-00562271 also inhibits other kinases such as c-Src and insulin growth factor 1 receptor (IGF1R) with less selectivity (IC50 value of $797 \mathrm{nM}$ and IC50 > $500 \mathrm{nM}$ respectively). This inhibitor has shown a broad preclinical activity. ${ }^{113}$ In PC3 human prostate tumor cells, PF-00562271 treatment blocks, anchorage independent tumor cell growth and tumor cell migration in vitro, has shown antitumoral effects in vivo. ${ }^{11}$ PF-00562271 decreases FAK phosphorylation-status in vitro and shows antitumor efficacy in vivo, in xenografts from: human colon; breast; prostate; pancreatic; and hepatocellular carcinoma tumor cell lines. ${ }^{113-115}$ No weight loss, or increase in morbidity and mortality were observed in any in vivo experiment and tumor growth inhibition was dose and drug exposure dependent. Furthermore, PF-562271 also showed an additional antiangiogenic effect over tumors. ${ }^{113}$ PF-562271 through the inhibition of FAK and PYK2 kinases may interfere with the ability of endothelial tumor cells to migrate, thus blocking the sprouting and stabilization of the new tumor vessels. ${ }^{63,116}$ PF-00562271 treatment has also led to the blockade of the expression of pro-angiogenic growth factors in tumor cells, such as VEGF. ${ }^{70}$ Recently, Bagi and colleagues showed that PF-00562271 synergized with antiangiogenic agents that directly block VEGF signaling, through its ability to target different aspects of angiogenesis and tumor aggressiveness. ${ }^{115}$ In addition, these authors show that the combination of these agents not only led to the blockade of tumor growth, it also impacted upon the ability of the tumor to recover on withdrawal of the therapy. PF-562,271 has also showed an in vivo effect in preventing the loss of bone, suggesting its potential activity in patients with bone metastases and cancer-associated osteoporosis. ${ }^{117}$ Therefore, PF-562,271 may comprise of a combined action over tumors: antiproliferative; proapoptotic; antiangiogenic; and antimetastatic action. Based on the preclinical data, a dose escalation phase 1 clinical trial with PF-562,271, administered orally as a single agent, in patients with solid tumors is currently underway. Tumor responses with PF-562,271 have been already reached in ovarian, colon together with head and neck cancer patients. Preliminary results showed a manageable safety profile with PF-562,271. In addition, continuous oral dosing is feasible and may be extended over 6 to 12 months in the majority of patients. The most common adverse events in the 32 evaluated patients with monitored safety data was: nausea in 14 patients ( $<$ Grade 3 ); vomiting in 12 patients (only 1 patient with Grade $\geq 3$ ); fatigue in 8 patients ( $<$ Grade 3 ); and diarrhea in 6 patients ( $<$ Grade $3)$. Prolonged disease stabilization has already been observed in a variety of solid tumors. However, the maximum tolerated dose (MTD) and recommended Phase 2 dose have still to be published. ${ }^{15,16}$ In addition to PF 573,228, a closely related, early prototype FAK inhibitor ${ }^{118}$ has been reported to have appealing activity in combating ovarian cancer metastases, ${ }^{119,120}$ demonstrating the growing body of evidence that supporting research of Src/FAK inhibitors in epithelial carcinoma.

\section{TAE 226}

TAE 226 is a low molecular weight, ATP-competitive tyrosine kinase inhibitor of FAK and IGF1R with an IC50 range of 100 to $300 \mathrm{nM} / \mathrm{L} .^{121}$ TAE 226 is still under preclinical development. Flow cytometry analysis of human glioma cell lines under TAE 226 treatment have shown an increase in the apoptotic and G0 (quiescent/nonproliferative) fractions after treatment, when these cells were compared with control/ nontreated cells. ${ }^{60}$ TAE 226 induced-apoptosis in the glioma tumor model is mediated by caspases and is correlated with the p53 status. In fact, apoptosis was only induced in the subset of glioma cell lines containing the mutant p53 gene. ${ }^{60}$

Additionally, TAE 226 treatment also prevented the in vitro attachment of these glioma cell lines. Furthermore, an in vivo intracranial glioma xenograft model showed a significantly higher median survival in the group of mice treated with TAE 226, at concentrations of 50-75 mg/ $\mathrm{kg}$. The treatment of ovarian cancer cell lines with TAE 226 inhibited cell growth in both a time- and dose-dependent manner; and enhanced docetaxel-mediated growth inhibition by 10 and 20 fold in the taxane-sensitive and taxane-resistant ovarian cell lines, respectively. In addition, TAE 226 alone and in combination with chemotherapy significantly prolonged survival in tumor-bearing mice. The efficacy of TAE 226 was related to: reduced pericyte coverage; the induction of apoptosis of tumor-associated endothelial cells; reduced microvessel density and tumor cell proliferation. ${ }^{121}$ TAE 226 also displayed an antitumoral effect in human pancreatic cell lines, ${ }^{122}$ esophageal cancer cell lines and xenografts, by a potent inhibition of PI3K-AKT-mTOR cell survival signaling. ${ }^{123}$ Clinical trials with this new dual FAKIGF1R inhibitor are planned. Recently, interesting experiments have suggested that the FAK-IGF-1R interaction site could be targeted; the specific disruption of this protein-protein interaction with another small molecule inhibitor(INT2-31) reinforces the potential novel role of this antineoplastic strategy. ${ }^{124}$

\section{FAK/Src and chemotherapy resistance}

As we mentioned above, an association between FAK activation and resistance to chemotherapy has been broadly reported in human tumor models. ${ }^{72,73,125-128}$ Accordingly, the combination of conventional chemotherapeutic drugs with 
FAK-targeting agents apparently offers greater efficacy in preclinical models than chemotherapy as a single agent. Treatment with FAK antisense oligonucleotides significantly induced apoptosis in human glioblastoma cells associated with a decrease in FAK protein levels. ${ }^{129}$ The in vitro cytotoxic effect achieved with the anti-FAK agent in monotherapy was almost the same as those obtained with different chemotherapeutic regimens such as cisplatin, etoposide and nimustine hydrochloride. ${ }^{129}$ When FAK antisense oligonucleotides and chemotherapy were administered in combination the antitumoral effect was clearly additive. ${ }^{129}$ Treatment of squamous cell carcinoma models with recombinant FRNK peptides combined with etoposide, paclitaxel or 5-FU also showed an additive antitumoral effect. ${ }^{127}$

The effect of combined chemotherapy and anti-FAK agents were also explored in human HCC cells in vitro. ${ }^{130}$ When TNF$\alpha$ plus cycloheximide was combined with FAK-antisense, an increase in the apoptotic index was observed. ${ }^{130}$ Additionally, FAK siRNA was also able to potentiate gemcitabine action in pancreatic cancer cells ${ }^{73}$ increasing the apoptotic index. The in vivo treatment with FAK siRNA, in combination with gemcitabine, induced in a statistically significant manner, a larger inhibition in the size of the tumors than gemcitabine in monotherapy. ${ }^{73}$ FAK siRNA incorporated in liposomes was administered to mice bearing tumors from human ovarian cancer cells. ${ }^{131}$ Mice treated with siRNA-DOPC showed a decrease in tumor weight. Docetaxel in combination with siRNA-DOPC resulted in an even greater reduction in tumor weight. ${ }^{131}$ This combination also showed: antiangiogenic properties; ${ }^{131}$ it decreased microvessel density; VEGF and MMP-9 secretion; and increased apoptosis in tumor cells, in addition to tumor-associated endothelial cells. ${ }^{131}$ Treatment with siRNA-DOPC resulted in a decrease in the tumor weight of cisplatin-resistant xenografts as well. ${ }^{131}$ These data suggest that the combination of anti-FAK agents with docetaxel or cisplatin may be a valuable therapeutic approach in the chemotherapy of resistant ovarian cancer. Smith and colleagues showed that FAK downregulation enhanced the effects of 5-FU in human melanoma cells. ${ }^{132}$ FAK antisense oligonucleotides significantly increased cell detachment and apoptosis when they were administered alone or in combination with 5 FU. ${ }^{132}$ This led to the decrease in FAK protein levels, an effect that was also observed with the 5-FU alone. Accordingly, FAK blockade plus 5-FU showed and additive effect.

There are also, preclinical data supporting the role of Src in chemoresistance. The inhibition of Src reversed chemoresistance toward 5-FU in human pancreatic carcinoma cells. ${ }^{74}$ Furthermore, Src inhibition also impaired both inherent and acquired gemcitabine resistance in human pancreatic adenocarcinoma cells. ${ }^{75}$ The combination of dasatinib and chemotherapy (5'-5'-DFUR or cisplatin) was synergistic in triple-negative breast cancer cells. ${ }^{99}$ In addition, phase 1 clinical trials are currently ongoing, with the Src inhibitor dasatinib in combination with chemotherapy in solid tumors. ${ }^{94,133}$

Interestingly the combination of paclitaxel/carbolatin standard chemotherapy in ovarian cancer has shown interesting synergism from this combined approach at the cell line level, that requires further investigation. ${ }^{134}$

In conclusion, current evidence shows that FAK/ Src-targeting compounds enhance the action of conventional anticancer agents at least in preclinical tumor models. Nonetheless, further molecular studies testing the activation status of both kinases in tumor biopsies and clinical trials, with anti-FAK/anti-Src agents and different chemotherapeutic schedules are still required to confirm if this complex is involved in treatment resistance and if the combination can enhance the efficacy of conventional chemotherapy in the clinical setting.

\section{The interest of targeting FAK and Src in breast cancer}

The Src/FAK signaling pathway is related to multiple receptor tyrosine kinases (RTKs) and intracellular mediators with a prominent role in the biology of the different subtypes of breast cancer. ${ }^{135}$

On one hand, c-Src interacts with and contributes to the signaling cascade of different RTKs; modulates their turnover by interfering in the endocytosis; and ubiquitination; in to taking part in the cytoskeleton rearrangement, migration and survival processes started at the RTKs' level in tumor cells. ${ }^{7}$ In breast cancer there is evidence of the interaction between c-Src and EGFR, (although short of a synergistic activity), connected to the crosstalk between estrogen receptor (ER) and EGFR. ${ }^{136,137}$ HER2 is coexpressed with c-Src in breast cancer ${ }^{138}$ and their interaction seems to facilitate the migratory and metastatic phenotype of these cells. ${ }^{139,140}$ Likewise, HER2 is actually involved in c-Src regulation, ${ }^{140}$ another mechanism of activation of HER2 such as the transactivation through G-protein receptors (ie, CXCR4). ${ }^{141} \mathrm{C}$-Src has also been proposed to be involved in the modulation of HER2-HER3 heterocomplexes in an intracellular mediated pattern. ${ }^{142}$

However, Src has also been linked to the endoplasmic reticulum (ER) nongenomic activity ${ }^{143}$ and the homeostasis of the ER ${ }^{144}$ in the tumor cells.

Src inhibitors have been developed in different breast cancer subtypes. Triple negative breast cancer has emerged 
as a potential field to be explored by this family of drugs. Two independent groups have described genetic profiles associated with a response to dasatinib ${ }^{95,145}$ highlighting the particular sensitivity of the basal-like phenotype to this Src inhibitor. This molecular marker approach has led to a phase 2 trial in the clinical setting ${ }^{146}$ showing modest, although encouraging, results to be tested in further trials, in combination with chemotherapy.

Hormone receptor-positive breast cancer, resistant to the classic endocrine therapy strategies, has become another field actively studied. In the tamoxifen resistance setting, the upregulation of different RTKs' signaling pathways has been involved. It has been suggested that the resistant phenotype is not just the result of an estrogen independent growth, ${ }^{147}$ but is also linked to an alteration in the relationship between the cells and the extracellular matrix, so that these tumor cells acquire an invasive and migratory phenotype ${ }^{148,102}$ that favors tumor dissemination. It has been demonstrated that anti-HER2 therapies are able to eliminate the agonist effect of tamoxifen, restoring its antitumoral capacity ${ }^{149}$ and the blockade of both pathways, showing an increased efficacy against endocrine-resistant tumors. ${ }^{100,150,151}$

However, these combinations have not shown a definitive effect regarding the migratory and invasive phenotype, ${ }^{148}$ moreover, the tumoral cells eventually develop double resistance that results in an even more invasive behavioral pattern. ${ }^{102,152}$ This dual resistant phenotype is characterized by an increase Src kinase activity, that defines another opportunity to target endocrine resistant breast cancer. The in vitro utility of Src inhibitors; due to the Src/FAK relationship in the acquisition of endocrine resistance in breast cancer, has already been tested. ${ }^{153-156}$ However, a recent article showed an opposite role for Src in breast cancer. Campbell and colleagues analyzed 262 breast cancer specimens, before tamoxifen treatment, for active Src expression by tissue microarray. The authors showed that phosphorylated c-Src in the nucleus was significantly associated with improved patient outcome in ER-positive breast cancer. ${ }^{157}$ The current findings suggest a crosstalk between ER and Src/FAK kinases, so that the addition of agents that block Src and/or FAK to hormonal therapy may improve the efficacy of the current endocrine therapies (aromatase inhibitors and tamoxifen). Clinical trials in breast cancer patients with dasatinib and aromatase inhibitors are underway in breast cancer patients. ${ }^{94}$

\section{Conclusions}

As we reviewed above FAK and Src form a mutually activated complex that acts as a common intracellular point of convergence in the signaling initiated by a variety of membrane receptors (RTKs, Integrins, G-coupled receptors, ER and others) to trigger a cascade of phosphorylation events and new protein-protein interactions in tumor cells and tumor endothelial cells, that allow the angiogenic and metastatic behavior of tumors. In fact, preclinical data with anti-Src and anti-FAK agents under development show that both types of inhibitors lead to antiproliferative, antiangiogenic and antimetastatic responses in human tumor models; a synergistic effect with other anticancer agents has been also observed. Therefore the inhibition of one of these kinases appears to be a successful therapeutic approach to avoid recurrence and dissemination of the primary tumor and also the progression of metastatic lesions.

Currently, we have robust data to believe FAK and c-Src inhibitors as a novel and promising anticancer strategy to combine with current anticancer therapies. A synergistic effect has already been shown when they are combined with other antitarget agents (ie, gefitinib, imatinib and sunitinib). Furthermore, these drugs have also been shown to be good candidates in the avoidance of chemotherapy and hormonotherapy resistances.

In addition, although it remains difficult to asses the efficacy of antimetastatic agents in the clinical setting, its appears that the inhibition of Src and FAK may have a potent anti-invasive effect, to delay tumor dissemination rather than real tumor shrinkage. Furthermore, although levels have already been seen as a possible predictor of response to Src inhibitors there is still a lack of suitable biomarkers that would be able to predict a response to these agents. In addition to current clinical studies of biomarker assays, the use of more sophisticated imaging technologies and the testing of the tumor, guided by biochemical rational, will help to maximize the development of these new compounds.

We have reviewed those trials with FAK and Src inhibitors under clinical development as a single agent or in combination with other therapeutic approaches. They have already shown clinical benefits in cancer patients with solid tumors. The identification of useful biomarkers to assess target inhibition, anti-invasive efficacy and predict treatment response will be crucial for future clinical trials.

\section{Acknowlegments}

We would like to thank to Nieves Ruíz-Ayllón for the editorial assistance. The authors report no conflicts of interest relevant to this research. 


\section{References}

1. Guo W, Giaconti FG. Integrin signaling during tumor progression. Nat Rev Mol Cell Biol. 2004;5(10):816-826.

2. Calalb MB, Polte TR, Hanks SK. Tyrosine of focal adhesion kinase at sites in the catalytic domain regulates kinase activity: a role for Src family kinases. Mol Cell Biol. 1995;15:954-963.

3. Satyajit K Mitra, David D Schlaepfer. Integrin-regulated FAK-Src signaling in normal and cancer cells. Current Opinion in Cell Biology. 2006;18(5):516-523.

4. Bruton VG, MacPherson IRJ, Frame MC. Cell adhesion receptors, tyrosine kinases and actin modulators: a complex three-way circuitry. Biochim Biophys Acta. 2004;1692:121-144.

5. Playford MP, Schaller MD. The interplay between Src and integrins in normal and tumor biology. Oncogene. 2004;18;23(48): 7928-7946.

6. Wang SE, Xiang B, Zent R, Quaranta V, Pozzi A, Arteaga CL. Transforming growth factor beta induces clustering of HER2 and integrins by activating Src-focal adhesion kinase and receptor association to the cytoskeleton. Cancer Res. 2009;69(2):475-478.

7. Bromann PA, Korkaya H, Courtneidge SA. The interplay between Src family kinases and receptor tyrosine kinases. Oncogene.2004;23(48): 7957-7968.

8. Chiang AC, Massagué J. Molecular basis of metastasis. N Engl J Med. 2008;359(26):2814-2823.

9. Van Nimwegen MJ, Van Dewater B. Focal adhesion kinase: a potential target in cancer therapy. Biochem Pharmacol. 2007;73:597-609.

10. Morgan L, Nicholson RI, Hiscox S. SRC as a therapeutic target in breast cancer. Endocr Metab Immune Disord Drug Targets. 2008;8(4):273-278.

11. Parsons JT, Slack-Davis J, Tilghman R, Roberts WG. Focal adhesion kinase: targeting adhesion signaling pathways for therapeutic intervention. Clin Cancer Res. 2008;14(3):627-632.

12. Finn RS. Targeting Src in breast cancer. Ann Oncol. 2008;19(8): 1379-1386.

13. Slack-Davis JK, Martin KH, Tilghman RW, Iwanicki M. Cellular characterization of a novel focal adhesion kinase inhibitor. J Biological Chem. 2007;282(20):14845-14852.

14. Jarkowski A, Sweeney RP. Nilotinib: a new tyrosine kinase inhibitor for the treatment of chronic myelogenous leukemia. Pharmacotherapy. 2008;28(11):1374-1382.

15. Siu LL, et al. Phase 1 study of a focal adhesion kinase (FAK) inhibitor PF-00562271 in patients (pts) with advanced solid tumors. Abstract 3527. 2007 ASCO Annual Meeting. Chicago, IL, USA.

16. Siu LL, et al. A phase I clinical, pharmacokinetic (PK) and pharmacodynamic (PD) evaluation of PF-00562271 targeting focal adhesion kinase (FAK) in patients (pts) with advanced solid tumors. Abstract 3534. 2008 ASCO Annual Meeting. Chicago, IL, USA.

17. Araujo J, Armstrong AJ, Braud EL, et al. Dasatinib and docetaxel combination treatment for patients with castration-resistant progressive prostate cancer: A phase I/II study (CA180086). Abstract 5061. 2009 ASCO Annual Meeting. Chicago, IL, USA.

18. Kluger HM, Dudek A, McCann C, et al. A phase II trial of dasatinib inadvanced melanoma. Abstract 9010. 2009 ASCO Annual Meeting. Chicago, IL, USA.

19. Mayer E, Baurain J, Sparano J, et al. Dasatinib in advanced HER2/neu amplified and ER/PR-positive breast cancer: Phase II study CA180088. Abstract 1011. 2009 ASCO Annual Meeting. Chicago, IL, USA.

20. Rous PA. Transmission of a malignant new growth by means of a cell-free filtrate. JAMA. 1911;56:198-202.

21. Rous PA. A sarcoma of the fowl transmissible by an agent separable from the tumor cells. $J$ Exp Med. 1911;13(4):397-411.

22. Steven Martin G. The hunting of the Src. Nature Rev Molec Cell Biol. 2001;2:467-475.

23. Yeatman TJ. A renaissance for SRC. Nat Rev Cancer. 2004;4(6): 470-480.

24. Ingley E. Src family kinases: regulation of their activities, levels and identification of new pathways. Biochim Biophys Acta. 2008; 1784(1):56-65.
25. Cox BD, Natarajan M, Stettner MR, Gladson CL. New concepts regarding focal adhesion kinase promotion of cell migration and proliferation. J Cell Biochem. 2006;99(1):35-52.

26. Kanner SB, et al. Monoclonal antibodies to individual tyrosinephosphorylated protein substrates of oncogene-encoded tyrosine kinases. Proc Natl Acad Sci. 1990:87(9):3328-3332.

27. Shaller MD, Borgman CA, Cobb BS, et al. pp125FAK a structurally distinctive protein-tyrosine kinase associated with focal adhesions. Proc Natl Acad Sci. 1992;89:5192-5196.

28. Schaller MD, Parsons JT: Focal adhesion kinase and associated proteins. Curr Opin Cell Biol. 1994;6:705-771.

29. Brunton VG, Avizienyte E, Fincham VJ, et al. Identification of Src-specific phosphorylation site on focal adhesion kinase: dissection of the role of Src SH2 and catalytic functions and their consequences for tumor cell behavior. Cancer Res. 2005;65(4):1335-1342.

30. Avizienyte E, Wyke AW, Jones RJ, et al. Src-induced de-regulation of E-cadherin in colon cancer cells requires integrin signaling. Nat Cell Biol. 2002;4(8):632-638.

31. Sieg DJ, Hauck CR, Ilic D, et al. FAK integrates growth-factor and integrin signals to promote cell migration. Nat Cell Biol. 2000;2(5):249-256.

32. Eliceiri BP, Puente XS, Hood JD, et al. Src-mediated coupling of focal adhesion kinase to integrin alpha(v)beta5 in vascular endothelial growth factor signaling. $J$ Cell Biol. 2002;157(1):149-160.

33. Schaller MD, Borgman CA, Parsons JT. Autonomous expression of a noncatalytic domain of the focal adhesion associated protein tyrosine kinase pp.125FAK. Mol Cell Biol. 1993;13:785-791.

34. Mitra SK, Schaepfer DD. Integrin-regulated FAK-C-src signaling in normal and cancer cells. Curr Opin Cell Biol. 2006;18:516-523.

35. Zhao J, Guan JL. Signal transduction by focal adhesion kinase in cancer. Cancer Metastasis Rev. 2009;28(1-2):35-49.

36. Parsons JT, Martin KH, Slack JK, Taylor JM. Focal adhesion kinase: a regulator of focal adhesion dynamics and cell movement. Oncogene. 2000;19(49):5606-5613.

37. Summy JM, Gallick GE. Src family kinases in tumor progression and metastasis. Cancer Metastasis Rev. 2003;22:337-358.

38. Ilic D, Furuta Y, Kanazawa S, et al. Reduced cell motility and enhanced focal adhesion contact formation in cells from FAK-deficient mice. Nature 1995;377:539-544.

39. Peng X, Ueda H, Zhou H, et al. Overexpression of focal adhesion kinase in vascular endothelial cells promotes angiogenesis in transgenic mice. Cardiovascular Res. 2004;64:421-430.

40. Weis SM, Lim ST, Lutu-Fuga KM, et al. Compensatory role for Pyk2 during angiogenesis in adult mice lacking endothelial cell. FAK. $J$ Cell Biol. 2008;181:43-50.

41. Guinamard R, Okigaki M, Schlessinger J, Ravetich JV. Absence of marginal zone B cell in Pyk2-deficient mice defines their role in the humoral response. Nat Immunol. 2000;1:31-36.

42. Okigaki M, Davis C, Falasca M, et al. Pyk2 regulates multiple signaling events crucial for macrophage morphology and migration. Proc Nat Acad Sci. 2003;100:10740-10745.

43. Lim ST, Chen XL, Lim Y, et al. Nuclear FAK promotes cell proliferation and survival through FERM-enhanced p53 degradation. Mol Cell. 2008;29(1):9-22.

44. Soriano P, Montgomery C, Geske R, Bradley A. Targeted disruption of the c-src proto-oncogene leads to osteopetrosis in mice. Cell. 1991;64(4):693-702.

45. Roodman GD: Mechanisms of bone metastasis. $N$ Engl J Med. 2004;350:1655-1664.

46. Rucci N, Susa M, Teti. Inhibition of protein kinase c-Src as a therapeutic approach for cancer and bone metastases. Anticancer Agents Med Chem. 2008;8(3):342-349.

47. Zhan M, Zhao H, Han ZC. Signaling mechanisms of anoikis. Histol Histopathol. 2004;19(3):973-983.

48. Duxbury MS, Ito H, Zinner MJ, Ashley SW, Whang EE. Focal adhesion kinase gene silencing promotes anoikis and suppresses metastasis of human pancreatic adenocarcinoma cells. Surgery. 2004;135(5):555-562.

49. Liu G, Meng X, Jin Y, et al. Inhibitory role of focal adhesion kinase on anoikis in the lung cancer cell A549. Cell Biol Int. 2008;32(6):663-670. 
50. Díaz-Montero CM, Wygant JN, McIntyre BW. PI3-K/Akt-mediated anoikis resistance of human osteosarcoma cells requires Src activation. Eur J Cancer. 2006;42(10):1491-500.

51. Gabarra-Niecko V, Schaller MD, Dunty JM. FAK regulates biological processes important for the pathogenesis of cancer. Cancer Metastasis Rev. 2003;22(4):359-374.

52. Grisaru-Granovsky S, Salah Z, Maoz M, Pruss D, Beller U, Bar-Shavit R Differential expression of protease activated receptor 1 (Par1) and pY397FAK in benign and malignant human ovarian tissue samples. Int $J$ Cancer. 2005;113(3):372-378.

53. Recher C, Ysebaert L, Beyne-Rauzy O, et al. Expression of focal adhesion kinase in acute myeloid leukemia is associated with enhanced blast migration, increased cellularity, and poor prognosis. Cancer Res. 2004;64(9):3191-3197.

54. Aronsohn MS, Brown HM, Hauptman G, Kornberg LJ. Expression of focal adhesion kinase and phosphorylated focal adhesion kinase in squamous cell carcinoma of the larynx. Aronsohn MS, Brown HM, Hauptman G, Kornberg LJ.

55. Moon HS, Park WI, Choi EA, Chung HW, Kim SC. The expression and tyrosine phosphorylation of E-cadherin/catenin adhesion complex, and focal adhesion kinase in invasive cervical carcinomas. Int J Gynecol Cancer. 2003;13(5):640-646.

56. Ding J, Li D, Wang X, Wang C, Wu T. Fibronectin promotes invasiveness and focal adhesion kinase tyrosine phosphorylation of human colon cancer cell. Hepatogastroenterology. 2008;55(88):2072-2076.

57. Panta GR, Nwariaku F, Kim LT. RET signals through focal adhesion kinase in medullary thyroid cancer cells. Surgery. 2004;136(6):1212-1217.

58. Panta GR, Du L, Nwariaku FE, Kim LT. Direct phosphorylation of proliferative and survival pathway proteins by RET. Surgery. 2005;138(2):269-274.

59. Tong Z, Kunnumakkara AB, Wang H, et al. Neutrophil gelatinaseassociated lipocalin: a novel suppressor of invasion and angiogenesis in pancreatic cancer. $S$ Cancer Res. 2008;68(15):6100-6108.

60. Liu TJ, LaFortune T, Honda T, et al. Inhibition of both focal adhesion kinase and insulin-like growth factor-I receptor kinase suppresses glioma proliferation in vitro and in vivo. Mol Cancer Ther. 2007;6(4): 1357-1367.

61. Schweppe RE, Kerege AA, French JD, Sharma V, Grzywa RL, Haugen BR. Inhibition of Src with AZD0530 reveals the Src-Focal Adhesion kinase complex as a novel therapeutic target in papillary and anaplastic thyroid cancer. J Clin Endocrinol Metab. 2009;94(6):2199-2203.

62. Chen J. Is Src the key to understanding metastasis and developing new treatments for colon cancer? Nat Clin Pract Gastroenterol Hepatol. 2008;5(6):306-307.

63. Haskell H, Natarajan M, Hecker TP, et al. Focal adhesion kinase is expressed in the angiogenic blood vessels of malignant astrocytic tumors in vivo and promotes capillary tube formation of brain microvascular endothelial cells. Clin Cancer Res. 2003;9(6):2157-2165.

64. Angelucci A, Bologna M. Curr. Targeting vascular cell migration as a strategy for blocking angiogenesis: the central role of focal adhesion protein tyrosine kinase family. Pharm Des. 2007;13(21):2129-2145.

65. Earley S, Plopper E. Disruption of focal adhesion kinase slows transendothelial migration of AU-565 breast cancer cells. Biochem Biophys Res Commun. 2006;350:405-412.

66. Eliceiri BP, Paul R, Schwartzberg PL, Hood JD, Leng J, Cheresh DA. Selective requirement for $\mathrm{C}$-src kinases during VEGF-induced angiogenesis and vascular permeability. Mol Cell. 1999;4:915-924.

67. Niu G, et al. Constitutive Stat 3 activity up-regulates VEGF expression and tumor angiogenesis. Oncogene. 2002;21:2000-2008.

68. Kilarski WW, Jura N, Gerwins P. Inactivation of Src family kinases inhibits angiogenesis in vivo: implications for a mechanism involving organization of the actin cytoskeleton. Exp Cell Res. 2003;291: 70-82.

69. Laird AD, et al. Src family kinase activity is required for signal tranducer and activator of transcription 3 and focal adhesion kinase phosphorylation and vascular endothelial growth factor signaling in vivo and for anchorage-dependent and-independent growth of human tumor cells. Mol Cancer Ther. 2003;2:461-469.
70. Sheta EA, Harding MA, Conaway MR, Theodorescu D. Focal adhesion kinase, Rap1, and transcriptional induction of vascular endothelial growth Factor. J Natl Cancer Inst. 2000;92(13):1065-1073.

71. Cascone I, Napione L, Maniero F, Serini G, Bussolino FJ. Stable interaction between alpha5beta1 integrin and Tie 2 tyrosine kinase receptor regulates endothelial cell response to Ang-1. Cell Biol. 2005;170(6):993-1004.

72. Halder J, Landen CN Jr, Lutgendorf SK, et al. Focal adhesion kinase silencing augments docetaxel-mediated apoptosis in ovarian cancer cells. Clin Cancer Res. 2005;11(24 Pt 1):8829-8836.

73. Duxbury MS, Ito H, Benoit E, Zinner MJ, Ashley SW, Whang EE. RNA interference targeting focal adhesion kinase enhances pancreatic adenocarcinoma gemcitabine chemosensitivity. Biochem Biophys Res Commun. 2003;311(3):786-792.

74. Ischenko I, Camaj P, Seeliger H, et al. Inhibition of Src tyrosine kinase reverts chemoresistance toward 5-fluorouracil in human pancreatic carcinoma cells: an involvement of epidermal growth factor receptor signaling. Oncogene. 2008;27(57):7212-7222.

75. Duxbury MS, Ito H, Zinner MJ, Ashley SW, Whang EE. Inhibition of SRC tyrosine kinase impairs inherent and acquired gemcitabine resistance in human pancreatic adenocarcinoma cells. Clin Cancer Res. 2004;10(7):2307-2318.

76. Duxbury MS, Ito H, Zinner MJ, Ashley SW, Whang EE. siRNA directed against c-Src enhances pancreatic adenocarcinoma cell gemcitabine chemosensitivity. J Am Coll Surg. 2004;198(6):953-959.

77. Shah AN, Gallick GE. Src, chemoresistance and epithelial to mesenchymal transition: are they related? Anticancer Drugs. 2007;18(4):371-375.

78. Mayer E, Baurain J, Sparano J, et al. Dasatinib in advanced HER2/neu amplified and ER/PR-positive breast cancer: Phase II study CA180088; Abstract: 1011. 2009 ASCO Annual Meeting, Chicago IL, USA.

79. Gutenberg A, Brück W, Buchfelder M, Ludwig HC. Expression of tyrosine kinases FAK and Pyk2 in 331 human astrocytomas. Acta Neuropathol. 2004;108(3):224-230.

80. Behmoaram E, Bijian K, Jie S, et al. Focal adhesion kinase-related proline-rich tyrosine kinase 2 and focal adhesion kinase are co-overexpressed in early-stage and invasive ErbB-2-positive breast cancer and cooperate for breast cancer cell tumorigenesis and invasiveness. Am J Pathol. 2008;173(5):1540-1550.

81. Sun CK, Ng KT, Sun BS, et al. The significance of proline-rich tyrosine kinase2 (Pyk2) on hepatocellular carcinoma progression and recurrence. Br J Cancer. 2007;97(1):50-57.

82. Iiizumi M, Bandyopadhyay S, Pai SK, et al. RhoC promotes metastasis via activation of the Pyk2 pathway in prostate cancer. Cancer Res. 2008;68(18):7613-7620.

83. Zhang S, Qiu X, Gu Y, Wang E. Up-regulation of proline-rich tyrosine kinase 2 in non-small cell lung cancer. Lung Cancer. 2008;62(3): 295-301.

84. Johnson FM, Gallick GE. SRC family nonreceptor tyrosine kinases as molecular targets for cancer therapy. Anticancer Agents Med Chem. 2007;7(6):651-659.

85. Thiery JP. Epithelial-mesenchymal transitions in development and pathologies. Curr Opin Cell Biol. 2003;15(6):740-746.

86. Peinado H, Olmeda D, Cano A. Snail, Zeb and bHLH factors in tumour progression: an alliance against the epithelial phenotype? Nat Rev Cancer. 2007;7(6):415-428.

87. Sabbah M, Emami S, Redeuilh G, et al. Molecular signature and therapeutic perspective of the epithelial-to-mesenchymal transitions in epithelial cancers. Drug Resist Updat. 2008;11(4-5):123-151.

88. Bailey KM, Liu JJ. Caveolin-1 up-regulation during epithelial to mesenchymal transition is mediated by focal adhesion kinase. Biol Chem. 2008;283(20):13714-13724.

89. Cicchini C, Laudadio I, Citarella F, et al. TGFbeta-induced EMT requires focal adhesion kinase (FAK) signaling. Exp Cell Res. 2008;314(1):143152 .

90. Mandal M, Myers JN, Lippman SM, et al. Epithelial to mesenchymal transition in head and neck squamous carcinoma: association of Src activation with E-cadherin down-regulation, vimentin expression, and aggressive tumor features. Cancer. 2008;112(9):2088-2100. 
91. Wei J, Xu G, Wu M, et al. Overexpression of vimentin contributes to prostate cancer invasion and metastasis via src regulation. Anticancer Res. 2008;28(1A):327-334.

92. Lombardo LJ, Lee FY, Chen P, et al. Discovery of N-(2-chloro6methylphneyl)-2-(6-(4-(2-hydroxyethyl)-piperazin-1-yl)-2methylpyrimidin-4-ylamino)thiazole-5 carboxamide (BMS-354825),a dual Src/Abl. kinase inhibitor with potent antitumor activityin pre-clinical assays. J Med Chem. 2004; 47(27):6658-6661.

93. Tokarski JS, Newitt JA, Chang CY, et al. The structure of Dasatinib (BMS-354825) bound to activated ABL kinase domain elucidates its inhibitory activity against imatinib-resistant ABL mutants. Cancer Res. 2006 1;66(11):5790-5797.

94. Kopetz S, Shah AN, Gallick GE. Src continues aging: current and future clinical directions. Clin Cancer Res. 2007;13(24): 7232-7236.

95. Finn RS, Dering J, Ginther C, et al. Dasatinib, an orally active small molecule inhibitor of both the src and abl kinases, selectively inhibits growth of basal-type/"triple-negative" breast cancer cell lines growing in vitro. Breast Cancer Res Treat. 2007;105(3): 319-326.

96. Huang F, Reeves K, Han X, et al. Identification of candidate molecular markers predicting sensitivity in solid tumors to dasatinib: rationale for patient selection. Cancer Res. 2007;67(5):2226-2238.

97. Park SI, Zhang J, Phillips KA, et al. Targeting SRC family kinases inhibits growth and lymph node metastases of prostate cancer in an orthotopic nude mouse mode. Cancer Res. 2008;68(9):3323-3333.

98. Xiao-Feng Le, Weiqun Mao, Zhen Lu, Robert C Bast Jr. Dasatinib induces autophagy as well as growth arrest in human ovarian cancer cells. Abstract 388. AACR 2009

99. Tryfonopoulos D, O’Donovan N, Corkery B, Clynes M, Crown J. Activity of dasatinib with chemotherapy in triple-negative breast cancer cells. Abstract: e14605. 2009 ASCO Annual Meeting, Chicago, IL, USA.

100. Seoane S, Montero JC, Pandiella A, Ocana A. Effect of dasatinib on the activity of trastuzumab in HER2- overexpressing breast cancer cells; Abstract: 1084. 2009 ASCO Annual Meeting, Chicago, IL, USA.

101. Hennequin LF, Allen J, Breed J, et al. N-(5-chloro-1,3-benzodioxol4-yl)-7-[2-(4-methylpiperazin-1-yl)ethoxy]-5-(tetrahydro-2Hpyran-4-yloxy)quinazolin-4-amine, a novel, highly selective, orally available, dual-specific c-Src/Abl kinase inhibitor. Med Chem. 2006;49(22):6465-6488.

102. Hiscox S, Morgan L, Green TP, Barrow D, Gee J, Nicholson RI. Elevated Src activity promotes cellular invasion and motility in tamoxifen resistant breast cancer cells. Breast Cancer Res Treat. 2006;97:263-274.

103. Hiscox S, Jordan NJ, Smith C, et al. Dual targeting of Src and ER prevent acquired antihormone resistance in breast cells. Breast Cancer Res Treat. 2009;115(1):57-67.

104. Chen Y, Guggisberg N, Jorda M, et al. Combined Src and Aromatase Inhibition Impairs Human Breast Cancer Growth In vivo and Bypass Pathways Are Activated in AZD0530-Resistant Tumors. Clin Cancer Res. 2009;15(10):3396-3405.

105. Herynk MH, Beyer AR, Cui Y, et al. Cooperative action of tamoxifen and c-Src inhibition in preventing the growth of estrogen receptor-positive human breast cancer cells. Mol Cancer Ther. 2006 5(12):3023-3031.

106. Clinical Trials.gov. Clinical Trials AZDO530 at: http://www. clinicaltrial.gov/ct2/results?term=AZD0530+ accessed March 2010

107. Stratford IJ, Telfer B, Green TP, et al. Inhibition of metastatic dissemination following loco-regional control of a primary tumor: examining a novel treatment paradigm with the Src kinase inhibitor AZD0530 Abstract 4946. AACR 2009.

108. Boschelli DH, Wu B, Ye F. Synthesis and Src kinase inhibitory activity of a series of 4-[(2,4-dichloro-5-methoxyphenyl)amino]7-furyl-3-quinolinecarbonitriles. J Med Chem. 2006;49(26): $7868-7876$.
109. Rabbani SA, Valentino ML, Ali S, Boschelli F. Inhibitor of Src kinase SKI-606 (Bosutinb) blocks prostate cancer growth, invasion and experimental skeletal metastases in vitro and in vivo by regulating the expression of key intracellular signaling molecules and genes involved in prostate cancer progression. Abstract 2325. AACR 2009.

110. Jallal H, Valentino ML, Chen G, Boschelli F, Ali S, Rabbani SA. A Src/Abl kinase inhibitor, SKI-606, blocks breast cancer invasion, growth, and metastasis in vitro and in vivo.Cancer Res. 2007;67(4): 1580-1588.

111. Messersmith WA, Krishnamurthi S, Hewes BA, et al. Bosutinib (SKI-606), a dual Src/Abl tyrosine kinase inhibitor: Preliminary results from a phase 1 study in patients with advanced malignant solid tumors. Abstract 3552. 2007 ASCO Annual Meeting. Chicago, IL, USA.

112. Clinical Trials.gov. Clinical Trials Bosutinib at: http://www. clinicaltrial.gov/ct2/results?term=Bosutinib+ accessed March 2010.

113. Roberts WG, Ung E, Whalen P, et al. Antitumor Activity and Pharmacology of a Selective Focal Adhesion Kinase Inhibitor, PF-562,271. Cancer Res. 2008;68(6):1935-1944.

114. Jayme B, Stokes SJ, Adair JK, et al. Targeting FAK in pancreatic cancer: a novel therapeutic approach. Abstract 843, AACR 2209.

115. Bagi CM, Christensen J, Cohen DP, et al. Sunitinib and PF-562,271 (FAK/Pyk2 inhibitor) effectively block growth and recovery of human hepatocellular carcinoma in a rat xenograft model. Cancer Biology and Therapy. 2009;8(9):856-865.

116. Cascone I, Napione L, Maniero F, Serini G, Bussolino FJ. Stable interaction between alpha5beta1 integrin and Tie2 tyrosine kinase receptor regulates endothelial cell response to Ang-1. Cell Biol. 2005;170(6):993-1004.

117. Bagi CM, Roberts GW, Andresen CJ. Dual focal adhesion kinase/Pyk2 inhibitor has positive effects on bone tumors: implications for bone metastases. Cancer 2008;112(10):2313-2321.

118. Slack-Davis JK, Martin KH, Tilghman RW, et al. Cellular characterization of a novel focal adhesion kinase inhibitor. J Biol Chem. 2007;282(20):14845-14852.

119. Stone RL, Nick AM, Spannuth W, et al. The clinical and biological significance of focal adhesion kinase activation in ovarian carcinoma. Abstract 3636. AACR 2009.

120. Dos Santos LA, et al. The FAK Inhibitor PF573228 Demonstrates Anti-proliferative and anti-invasive activity in MUC16/CA125 ovarian carcinoma cells. Abstract 3519. AACR 2009.

121. Halder J, Lin YG, Merritt WM, et al. Therapeutic efficacy of a novel focal adhesion kinase inhibitor TAE226 in ovarian carcinoma. Cancer Res. 2007;67(22):10976-10983.

122. Liu W, Bloom DA, Cance WG, Kurenova EV, Golubovskaya VM, Hochwald SN. FAK and IGF-IR interact to provide survival signals in human pancreatic adenocarcinoma cells. Carcinogenesis. 2008;29(6):1096-1107.

123. Hao H, Wang Z, Bao X, et al. Dual tyrosine kinase inhibitor for focal adhesion kinase and insulin-like growth factor-I receptor (TAE226) leads to apoptosis in esophageal cancer by inhibiting AKT-mTOR survival signaling. Abstract 1840. AACR 2009.

124. Ucar D, Kurenova E, Zheng D, et al. A novel small molecule that targets the FAK and IGF-1R site of interaction inhibits growth of human cancer. Abstract 2008. AACR 2009.

125. Villedieu M, Deslandes E, Duval M, Héron JF, Gauduchon P, Poulain L. Acquisition of chemoresistance following discontinuous exposures to cisplatin is associated in ovarian carcinoma cells with progressive alteration of FAK, ERK and p38 activation in response to treatment. Gynecol Oncol. 2006;101(3):507-519.

126. Van Nimwegen MJ, Huigsloot M, Camier A, Tijdens IB, van de Water B. Focal adhesion kinase and protein kinase B cooperate to suppress doxorubicin-induced apoptosis of breast tumor cells. Mol Pharmacol. 2006;70(4):1330-1339.

127. Kornberg LJ: Adenovirus-mediated transfer of FRNK augments drug-induced cytotoxicity in cultured SCCHN cells. Anticancer Res. 2005;25:4349-4356. 
128. Fang Y, Wang L, Jin J, et al. Ref Focal adhesion kinase affects the sensitivity of human hepatocellular carcinoma cell line SMMC-7721 to TNF- $\alpha /$ cycloheximide-induced apoptosis by regulating protein kinase B levels. Eur J Biochem. 2001;268:4513-4519.

129. Wu ZM, Yuan XH, Jiang PC, et al. Antisens oligonucleodes targeting the focal adhesion kinase inhibit proliferation, induce apoptosis and cooperate with cytotoxic drugs in human glioma cells. J Neurooncol. 2006;77:117-123.

130. Fang Y, Wang L, Jin J, Zha X. Focal adhesion kinase affects the sensitivity of human hepatocellular carcinoma cell line SMMC-7721 to TNF- $\alpha /$ cycloheximide-induced apoptosis by regulating protein kinase B levels. Eur J Biochem. 2001;268:4513-4519.

131. Halder J, Kamat AA, Landen CN Jr, et al. Focal adhesion kinase targeting using in vivo short interfering RNA delivery in neutral liposomes for ovarian carcinoma therapy. Clin Cancer Res. 2006;12(16): 4916-4924.

132. Smith CS, Golubovskaya VM, Peck E, et al. Effect of focal adhesion kinase (FAK) downregulation with FAK antisense oligonucleotides and 5-fluorouracil on the viability of melanoma cell lines. Melanoma Res. 2005;15(5):357-362.

133. Somlo G, Atzori F, Strauss L, et al. Dasatinib plus capecitabine (Cap) for progressive advanced breast cancer (ABC): Phase I study CA180004. Abstract: 1012. 2009 ASCO Annual Meeting, Chicago IL, USA.

134. Teoh D, Ayeni TA, Rubatt JM, et al. In vitrocharacterization of the antitumor effects of dasatinib (BMS-354825) in combination with paclitaxel and carboplatin in human ovarian cancer cell lines. Abstract 828. AACR 2009.

135. Summy JM, Gallick GE. Treatment for advanced tumors: SRC reclaims center stage. Clin Cancer Res. 2006;12(5):1398-1401.

136. Biscardi JS, Belsches AP, Parsons SJ. Characterization of human epidermal growth factor receptor and c-Src interactions in human breast tumor cells. Mol Carcinog. 1998;21(4):261-272.

137. Hitosugi T, Sasaki K, Sato M, Suzuki Y, Umezawa Y. Epidermal growth factor directs sex-specific steroid signaling through Src activation. $J$ Biol Chem. 2007;282(14):10697-10706.

138. Muthuswamy SK, Siegel PM, Dankort DL, Webster MA, Muller WJ. Mammary tumors expressing the neu proto-oncogene possess elevated c-Src tyrosine kinase activity. Mol Cell Biol. 1994;14(1): 735-743.

139. Elsches-Jablonski AP, Biscardi JS, Peavy DR, Tice DA, Romney DA, Parsons SJ. Src family kinases and HER2 interactions in human breast cancer cell growth and survival. Oncogene. 2001;20(12): 1465-1475.

140. Vadlamudi RK, Sahin AA, Adam L, Wang RA, Kumar R. Heregulin and HER2 signaling selectively activates c-Src phosphorylation at tyrosine 215. FEBS Lett. 2003;543(1-3):76-80.

141. Cabioglu N, Summy J, Miller C, et al. CXCL-12/stromal cellderived factor-1alpha transactivates HER2-neu in breast cancer cells by a novel pathway involving Src kinase activation. Cancer Res. 2005;65(15):6493-6497.

142. Ishizawar RC, Miyake T, Parsons SJ. c-Src modulates ErbB2 and ErbB3 heterocomplex formation and function. Oncogene. 2007;26(24): 3503-3510.
143. Song RX, Zhang Z, Santen RJ. Estrogen rapid action via protein complex formation involving ERalpha and Src. Trends Endocrinol Metab. 2005;16(8):347-353.

144. Chu I, Arnaout A, Loiseau S, et al. Src promotes estrogen-dependent estrogen receptor alpha proteolysis in human breast cancer. $J$ Clin Invest. 2007;117(8):2205-2215.

145. Huang F, Reeves K, Han X, et al. Identification of candidate molecular markers predicting sensitivity in solid tumors to dasatinib: rationale for patient selection. Cancer Res. 2007;67(5):2226-2238.

146. Finn RS, Bengala C, Ibrahim N, et al. Phase II Trial of Dasatinib in Triple-negative Breast Cancer: Results of Study CA180059. SABCS 2008.

147. Knowlden JM, Hutcheson IR, Jones HE, et al. Elevated levels of epidermal growth factor receptor/c-erbB2 heterodimers mediate an autocrine growth regulatory pathway in tamoxifen-resistant MCF-7 cells. Endocrinology. 2003;144(3):1032-1044.

148. Hiscox S, Morgan L, Barrow D, Dutkowskil C, Wakeling A, Nicholson RI. Tamoxifen resistance in breast cancer cells is accompanied by an enhanced motile and invasive phenotype: inhibition by gefitinib ('Iressa', ZD1839). Clin Exp Metastasis. 2004;21(3):201-212.

149. Nicholson RI, Hutcheson IR, Harper ME, et al. Modulation of epidermal growth factor receptor in endocrine-resistant, estrogen-receptorpositive breast cancer. Ann NY Acad Sci. 2002;963:104-115.

150. Massarweh S, Osborne CK, Jiang S, et al. Mechanisms of Tumor Regression and Resistance to Estrogen Deprivation and Fulvestrant in a Model of Estrogen Receptor-Positive, HER-2/neu-Positive Breast Cancer Cancer Res. 2006;66(16):8266-8273.

151. Shou J, Massarweh S, Osborne CK, et al. Mechanisms of tamoxifen resistance: increased estrogen receptor-HER2/neu cross-talk in ER/HER2-positive breast cancer. J Natl Cancer Inst. 2004;96(12): 926-935.

152. Hiscox S, Jordan NJ, Morgan L, Green TP, Nicholson RI. Src kinase promotes adhesion-independent activation of FAK and enhances cellular migration in tamoxifen-resistant breast cancer cells. Clin Exp Metastasis. 2007;24(3):157-167.

153. Planas-Silva MD, Bruggeman RD, Grenko RT, Stanley Smith J. Role of c-Src and focal adhesion kinase in progression and metastasis of estrogen receptor-positive breast cancer. Biochem Biophys Res Commun. 2006;341(1):73-81.

154. Planas-Silva MD, Hamilton KN. Targeting c-Src kinase enhances tamoxifen's inhibitory effect on cell growth by modulating expression of cell cycle and survival proteins. Cancer Chemother Pharmacol. 2007;60(4):535-543.

155. Planas-Silva MD, Waltz PK. Estrogen promotes reversible epithelialto-mesenchymal-like transition and collective motility in MCF-7 breast cancer cells. J Steroid Biochem Mol Biol. 2007;104(1-2): 11-21.

156. Chen Y, Guggisberg N, Jorda M, et al. Combined Src and Aromatase Inhibition Impairs Human Breast Cancer Growth In vivo and Bypass Pathways Are Activated in AZD0530-Resistant Tumors. Clin Cancer Res. 2009;15(10) 3396-3405.

157. Campbell EJ, McDuff E, Tatarov O, et al. Phosphorylated c-Src in the nucleus is associated with improved patient outcome in ER-positive breast cancer. Br J Cancer. 2008 Dec 2;99(11):1769-1774.
OncoTargets and Therapy

\section{Publish your work in this journal}

OncoTargets and Therapy is an international, peer-reviewed, open access journal focusing on the pathological basis of all cancers, potential targets for therapy and treatment protocols employed to improve the management of cancer patients. The journal also focuses on the impact of management programs and new therapeutic agents and protocols on

\section{Dovepress}

patient perspectives such as quality of life, adherence and satisfaction. The manuscript management system is completely online and includes a very quick and fair peer-review system, which is all easy to use. Visit http://www.dovepress.com/testimonials.php to read real quotes from published authors. 